\title{
Podredumbre basal de plantas adultas de tomate CAUSADA por PYTHIUM APHANIDERMATUM (ООMYCOTA)
}

\author{
PABLO E. GRIJALBA ${ }^{1}$, RAUL L. ZAPATA, HEMILSE E. PALMUCCI y CLAUDIO BARON
}

\begin{abstract}
Summary: Basal root rot of mature plants of tomato caused by Pythium aphanidermatum (Oomycota). In roots of adult tomato plants a wet and brown lesion, extending 2-4 cm above the soil was observed. Diseased plants withered and died. The objective of this paper was to isolate and to identify the causal organism of these symptoms. General and selective culture media were used. After 24 hours colonies with white cottony mycelium were developed. The morphology of the colony and the production, morphology and size of reproductive structures were evaluated. The rDNA extraction was made from mycelium of pure cultures 7-10 days old grown in agarized media. The ITS region was amplified using ITS4 and ITS5 primers, sequenced and compared in gene bank - NCBI BLAST server to verify their sequence similarity to the type or holotype available. Coenocytic mycelium, spherical-globular sporangium and aplerotic oospores, characteristic of the genus Pythium were observed in microscopic slides. Pathogenicity tests were conducted with positive results; a microorganism identical to the original was re-isolated. The characterization achieved by traditional techniques, molecular studies and the results of the pathogenicity tests support the conclusion that Pythium aphanidermatum is the causal agent of basal rot on mature plants of tomato .
\end{abstract}

Key Words: Oomycete, Pythium, Tomato.

\begin{abstract}
Resumen: En raíces de plantas adultas de tomate se observó una lesión castaña de aspecto húmedo, que se extendía 2-4 cm por encima del suelo. Las plantas atacadas se marchitaron y murieron. El objetivo del trabajo fue aislar e identificar al organismo causal de esta sintomatología. Se usaron medios de cultivos generales y selectivos. A las 24 horas desarrollaron colonias con micelio blanco algodonoso. Se evaluó la morfología de la colonia y la producción, morfología y dimensiones de estructuras reproductivas. El rDNA del micelio de un aislamiento fue extraído de cultivos puros con 7-10 días de crecimiento en medios agarizados. La región ITS se amplificó usando primers ITS4 e ITS5, se secuenció y comparó en banco de genes del servidor BLAST- NCBI para verificar su similitud con las secuencias tipo u holotipo disponibles. Al microscopio se observó micelio cenocítico, esporangios esfericos-globulados y oosporas apleroticas característicos del género Pythium. Se efectuaron pruebas de patogenicidad con resultados positivos reaislándose un microorganismo de características idénticas. La caracterización lograda por las técnicas tradicionales, los estudios moleculares y el resultado de las pruebas de patogenicidad permiten concluir que Pythium aphanidermatum es el causante de la Podredumbre basal de plantas adultas de Tomate.
\end{abstract}

Palabras claves: Oomycete, Pythium, Tomate.

\section{INTRODUCCION}

En plantas de tomates del cv. Chalchalero (cultivar tipo pera indeterminado de la compañía BHN) transplantados en enero de 2013 con temperaturas superiores a $\operatorname{los} 30^{\circ} \mathrm{C}$ en invernaderos del cinturón

1 Cátedra de Fitopatología, Facultad de Agronomía, Universidad de Buenos Aires. Av. San Martín 4453 CABA-1417. Argentina. grijalba@agro.uba.ar verde de La Plata, tanto en suelos desinfectados como en sectores con interplanting (segunda plantación realizada sobre un cultivo anterior), se observó una lesión castaña oscura a negra de aspecto húmedo. La misma tenía carácter ascendente desde la base del tallo (Fig. 1), manifestándose en plantas desde recién transplantadas, hasta que las mismas tuvieron 3-4 racimos cuajados (plantas de 1,20 m de altura y de 50 días de ciclo desde transplante). Las plantas atacadas se marchitaron sin perder su coloración verde y murieron. Las pérdidas de 


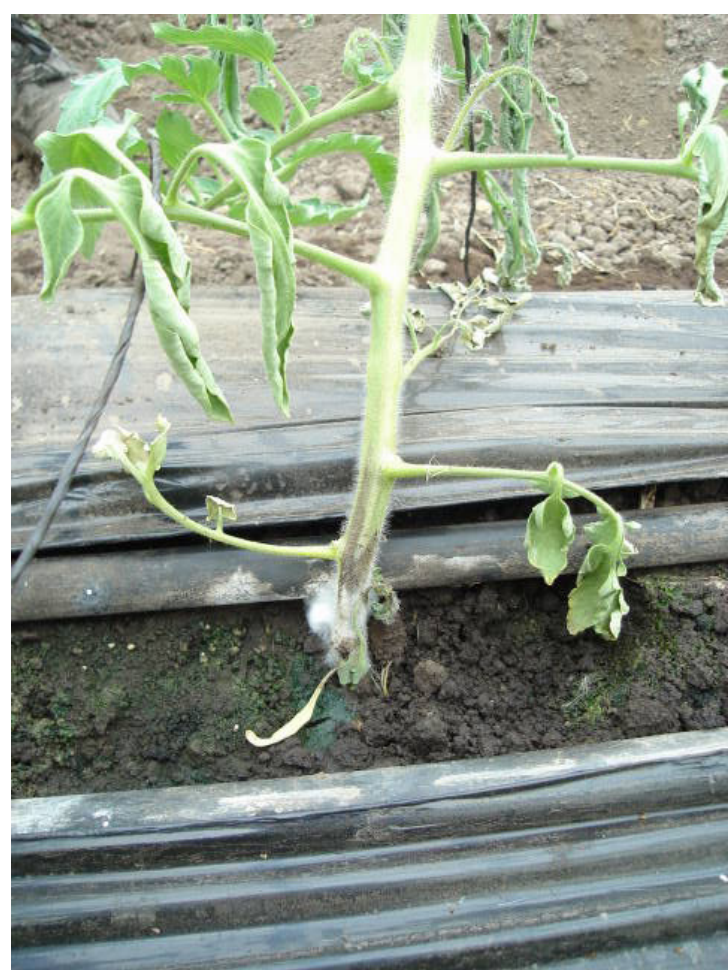

Fig. 1. Detalle de síntoma de podredumbre ascendente sobre planta adulta. Escala $=1 \mathrm{~cm}$.

plantas en lotes sin desinfectar, alcanzaban el 50\% cuando se decidió levantar el cultivo porque ya no resultaba redituable.

Varios patógenos de suelo atacan al cultivo de tomate en estadíos avanzados del cultivo, entre los que podemos citar a Phytophthora parasitica Dastur y Ph. capsici Leonian, produciendo síntomas como los descriptos. Sin embargo, al efectuar un test serológico específico para el género Phytophtora (Phytophthora ImmunoStrip ${ }^{\circledR}$ ) a partir de tejidos afectados, el resultado fue negativo. Jones et al, (2001), indican que las especies de Pythium aphanidermatum (Edson) Fitzp, P. myriotilum Drechs, P. arrheromanes Drechs., P. ultimun Trow. y $P$. debarianum R. Hesse. causan además de enfermedad en plántulas, la podredumbre del tallo de tomate. Generalmente $P$. aphanidermatum se encuentra mas asociado con la enfermedad en plántulas que otras especies, especialmente con temperaturas moderadas a altas. $P$. aphanidermatum. y $P$. myriotylum. atacan en ocasiones a plantas de una longitud de mas de 10 $\mathrm{cm}$, causando una lesión húmeda castaño oscura a negra, que puede llegar a extenderse $2-4 \mathrm{~cm}$ por encima del suelo. Generalmente, las plantas afectadas de esta manera se marchitan y mueren. El objetivo del presente trabajo fue determinar la etiología de la sintomatología observada.

\section{Materiales y Métodos}

Para aislar al patógeno, raíces necrosadas y base de tallo de plantas con síntomas se lavaron bajo agua de canilla, se cortaron pequeños trozos que se desinfectaron superficialmente con $\mathrm{NaOCl}$ al 1 $\%$ durante $2 \mathrm{~min}$ y posteriormente se lavaron dos veces con agua destilada estéril. Una vez secos se sembraron en medio Agar Papa Dextrozado (APD) PARP (Kannwischer y Mitchell, 1978) que se incubó en oscuridad a temperatura ambiente. A las 48 horas de la siembra se aisló un oomycete y se transfirieron puntas hifales a APD y a Corn Meal Agar (CMADifco Laboratories, Detroit). Cultivos puros, libres de contaminación bacteriana, fueron transferidos a CMA en tubos de ensayo y se almacenaron en heladera. La morfología de la colonia se observó después de una incubación durante 7 días a temperatura ambiente. Las características de los oogonios, anteridios y oosporas se determinaron cortando discos de agar de las colonias en activo crecimiento en APD, colocados sobre trocitos de césped (Agrostis sp.) sobrenadando en agua destilada estéril durante 48-72 hs, mantenidos en placas de plástico a temperatura ambiente y su posterior observación microscópica. Se efectuaron las pruebas de patogenicidad utilizando el aislamiento Pytom 1, desarrollado en medio APD en placas de Petri de $9 \mathrm{~cm}$ durante 4 días en estufa a $22{ }^{\circ} \mathrm{C}$. Se utilizaron plantines de tomate cv. Chalchalero al estado de tres hojas verdaderas, cultivados en invernadero en macetas plásticas de 12 $\mathrm{cm}$ con un sustrato comercial tindalizado dos veces con vapor de agua durante 1 hora. La inoculación se llevó a cabo incorporando el contenido de una placa por debajo de las raíces de cada plantín. En el tratamiento testigo se incorporó la placa de APD sin desarrollo miceliar alguno. Tanto las plantas inoculadas como las testigos se regaron hasta saturación y se mantuvo ese nivel de humedad durante todo el ensayo. Las plantas inoculadas se mantuvieron durante 21 días en condiciones de 
invernadero. Se efectuaron 5 repeticiones. Para corroborar la identificación morfológica se decidió complementar los resultados con una identificación molecular. Para ello el ADN del micelio de la cepa Pytom 1 se extrajo a partir de una colonia de 7 días de crecimiento en APD a $22^{\circ} \mathrm{C}$, utilizando un kit comercial (Wizard genomic, Promega Inc), según protocolo e instrucciones del proveedor. La región ITS del rADN nuclear se amplificó usando primers ITS4 (TCCTCCGCTTATTGATATGC) e ITS5 (GGAAGTAAAAGTCGTAACAAGG) (White et al., 1990). Las reacciones de amplificación se realizaron con un termociclador Perkin-Elmer (Perkin-Elmer Cetus, Emeryville, CA) y las condiciones fueron las siguientes: $50 \mathrm{mM} \mathrm{KCl}$; 2,5 mM MgCl2; $10 \mathrm{mM}$ Tris- $\mathrm{HCl}$ a $\mathrm{pH} 8,3 ; 0,2$ mM de cada dTTP, dATP, dGTP, y dCTP; 50 pmol de primers; 2,5 unidades de Taq polymerasa (Gibco BRL Corp., Grand Island, MD); y 25 ng de ADN genomico en un volumen final de $50 \mu$ l. Las reacciones se corrieron: 1 ciclo a $96^{\circ} \mathrm{C}$ durante 3 min y 30 ciclos a $94^{\circ} \mathrm{C}$ durante $1 \mathrm{~min}, 55^{\circ} \mathrm{C}$ durante $1 \mathrm{~min}, \mathrm{y} 72^{\circ} \mathrm{C}$ durante $2 \mathrm{~min}$. Cada corrida incluyó una reacción sin $\mathrm{ADN}$ (control negativo) para monitorear la contaminación potencial por ADN exógeno (Matsumoto et al., 1999). Los productos de amplificación se verificaron mediante electroforesis en un gel de agarosa al $1 \%$ con el agregado de buffer TBE $0,5 \times(0,045 \mathrm{M}$ Trizma base, 0,045 M ácido bórico, 0,001 M EDTA, pH $8,0)$, y se visualizaron en un trans-ilumninador con fluorescencia UV después de la tinción con bromuro de etidio. Para minimizar los errores de secuenciación, se obtuvieron las secuencias 5'-3' y 3'-5' y la secuencia consenso se ensambló utilizando el programa GeneTool Life 1.0 (Layon, 2000). La identificación de los fragmentos amplificados se determinó alineando la secuencia obtenida con las secuencias publicadas en el GenBank, utilizando el programa BLAST (Altschul et al., 1997).

\section{Resultados y Discusión}

El test serológico específico para el género Phytophthora dio resultado negativo y las características morfológicas se correspondieron con el género Pythium. Todos los aislamientos presentaron en APD micelio blanco algodonoso, observándose al microscopio hifas cenocíticas y esporangios lobados o filamentosos, un anteridio por oogonio comúnmente intercalar (Fig. 2), tanto monoclino como diclino, oogonios terminales y oosporas apleróticas que correspondían, según la descripción de van der Plaats-Niterink (1981), a Pythium aphanidermatum.

El test de patogenicidad arrojó resultados positivos, mediante la producción de una podredumbre húmeda basal de aspecto castaño y menor desarrollo de las raíces de las plantas inoculadas (Fig. 3). Los testigos correspondientes no presentaron sintomatología alguna y mostraron un buen desarrollo radicular. La secuencia del ITS del rDNA del aislamiento Pytom 1 (acceso genbank \# KF561235) se comparó con secuencias homólogas del NCBI GenBank y presentó 100\% de similitud con Pythium aphanidermatum cepa CBS 118.80 (\#AY598622). La cepa Pytom 1 fue almacenada en la colección de hongos de la cátedra de Fitopatología - Universidad de Buenos Aires. Cada vez son más utilizados los datos de secuencias moleculares junto con análisis filogenéticos para la identificación de especies, incluyendo al género Pythium. La primera filogenia molecular completa de Pythium fue publicado por Lévesque $\&$ de Cock (2004).

El re-aislamiento de las plantas inoculadas presentó idénticas características al aislamiento

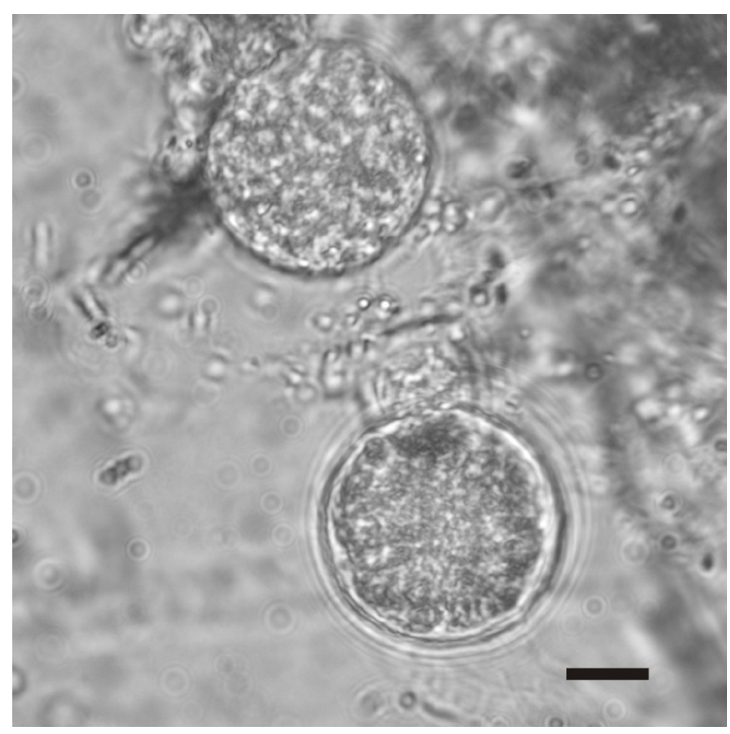

Fig. 2. Anteridio intercalar y oogonio de Pythium aphanidermatum. Escala: $=10 \mu \mathrm{m}$. 
Bol. Soc. Argent. Bot. 50 (1) 2015

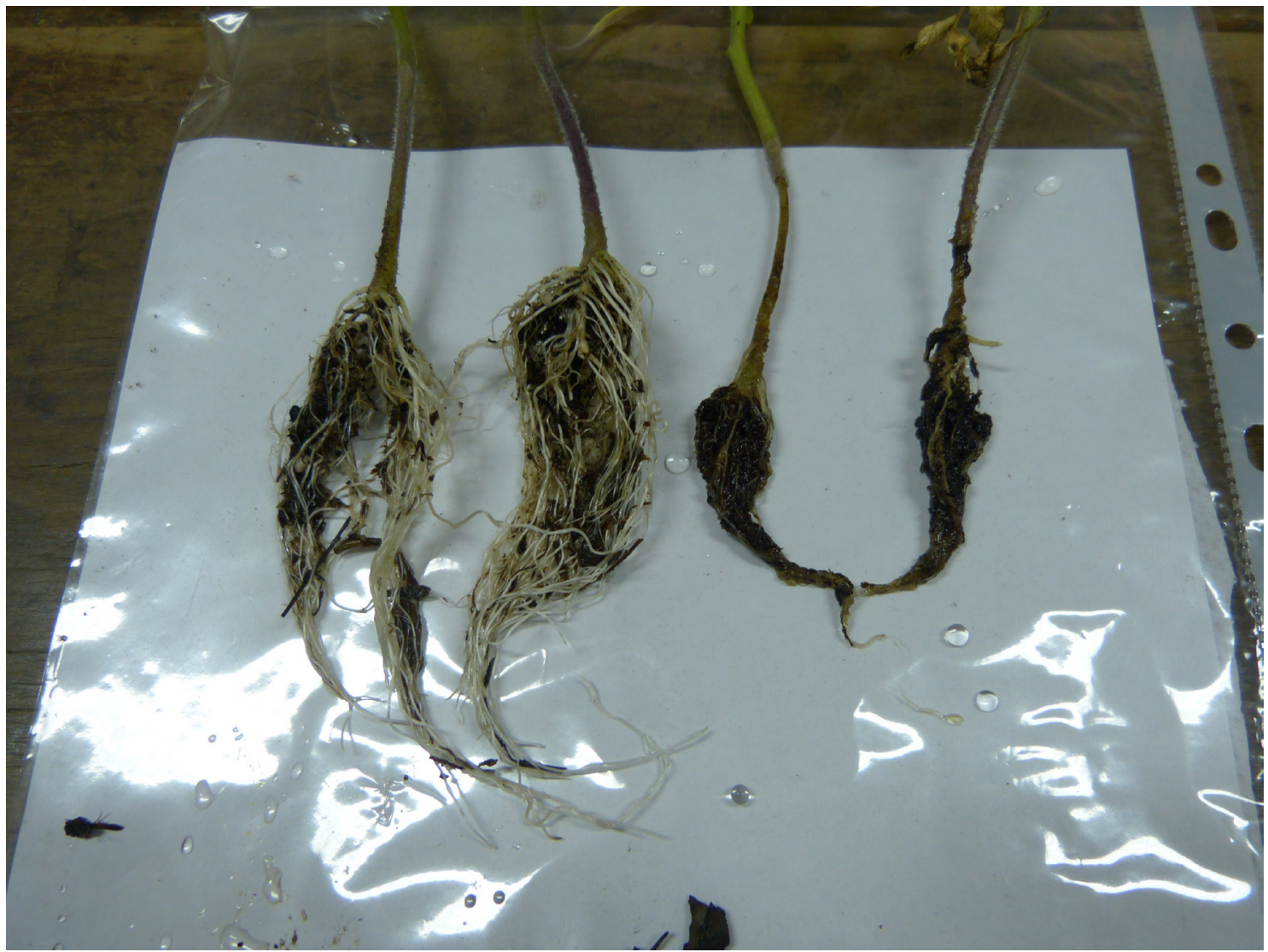

Fig. 3. Detalle del test de patogenicidad. Derecha: Plantas inoculadas. Izquierda: Plantas testigo. Escala = $1 \mathrm{~cm}$.

inicial. Los estudios culturales, morfológicos y moleculares y el resultado de las pruebas de patogenicidad permiten concluir que Pythium aphanidermatum es el causante de la podredumbre basal de plantas adultas de tomate. No todas las especies de Pythium son patógenas y la patogenicidad puede variar entre especies. Una correcta identificación es necesaria para adoptar medidas de manejo eficientes tan pronto como sea posible. $P$. aphanidermatum es más destructivo a teperaturas sobre los $25 \mathrm{C}$ (Stanghellini \& Rasmussen, 1994), mientras que P. ultimun es mas destructivo a temperaturas bajas (Jenkins \& Averre, 1983; Cherif \& Bélanger, 1992).

Se concluye que las condiciones térmicas extremas presentes al momento del transplante de los lotes citados en la introducción, predispusieron al cultivo al ataque de $P$. aphanidermathum. Si bien afecta a las plantas en sus primeros estadíos de almácigo o primer trasplante, ha sido reportada ocasionando la muerte de plantas adultas de Phaseolus vulgaris (poroto); Pisum sativum (arveja); Capsicum annum (pimiento); Euphorbia marginata (copo de nieve); Cereus aethiops (hachón-cactus) (Palmucci et al., 2011; Frezzi, 1956). P. aphanidermatum fue aislado por primera vez en 1950 en Manfredi (Provincia de Córdoba) a partir de plantas grandes de Pisum sativum (arveja) muertas por podredumbre radical causando aproximadamente $40 \%$ de mortandad. En 1953 provocó en poroto marchitamiento y muerte de plantas grandes debido a podredumbre parcial o total de raíces y necrosis del tallo, en cultivos de Villa Ascasubi (Prov. de Córdoba). Fue reportado en Manfredi (Prov. de Córdoba) ocasionando muerte de plantas grandes de pimiento (Capsicum annum) por podredumbre total de raíces y necrosis del tallo (Frezzi, 1956). Esta es la primera cita de 
P. aphanidermatum provocando estos síntomas en plantas adultas de tomate en la Republica Argentina.

\section{Conclusiones}

Los estudios culturales, morfológicos y moleculares y el resultado de las pruebas de patogenicidad permiten concluir que Pythium aphanidermatum es el causante de la podredumbre basal de plantas adultas de tomate. Las condiciones térmicas extremas presentes al momento del transplante predispusieron al cultivo al ataque de este patógeno.

\section{Bibliografia}

ALTSCHUL, S. F., T. L. MADDEN, A. A. SCHÄFFER, G. L. ZHANG, Z. ZHANG, W. MILLER W \& D. J. LIPMAN. 1997. Gapped BLAST and PSI-BLAST: a new generation of protein database search programs. Nucleic Acid Res 25:389-402.

CHERIF, M. \& R. R. BÉLANGER. 1992. Use of potassium silicate amendments in recirculating nutrient solutions to suppress Pythium ultimum on Long English cucumber. Plant Dis. 76: 1008-1011.

FREZZI, M. J. 1956. Especies de Pythium fitopatógenas identificadas en la República Argentina. Revista Invest. Agric. 10: 113-241.

JENKINS, S. F., JR \& C. W. AVERRE. 1983. Root diseases of vegetables in hydroponic culture systems in North Carolina greenhouses. Plant Dis. 67: 968970 .
JONES J. P., R. E. STALL \& T. A. ZITTER. 2001. Plagas y Enfermedades del Tomate. Ed. MUNDI-PRENSA. 100 pp. ISBN 9788471149435

KANNWISCHER, M. E. \& D. J. MITCHELL. 1978. The influence of a fungicide on the epidemiology of black shank of tobacco. Phytopatology 68:17601765.

LAYON M. 2000. GeneTool 1.0. Biotech Softw and Internet Rep 1:261-264.

LÉVESQUE C. A. \& A. W. DE COCK. 2004. Molecular phylogeny and taxonomy of the genus Pythium. Mycol. Res. 108 (12): 1363-1383

MATSUMOTO, C., K. KAGEYAMA, H. SUGA \& M. HYAKUMACHI. 1999. Phylogenetic relationships of Pythium species based on ITS and 5.8S sequences of the ribosomal DNA. Mycoscience 40: 321-331.

PALMUCCI H. E., S. M. WOLCAN \& P. E. GRIJALBA. 2011. Status of the Pythiaceae (Straminipila) in Argentina: I. The Genus Pythium. Bol. Soc. Argent. Bot. 46: 197-211.

STANGHELLINI, M. E. \& S. L. RASMUSSEN. 1994. Hydroponics. A solution for zoosporic pathogens. Plant Dis. 78: 1129-1138.

VAN DER PLAATS-NITERINK, A. J. 1981. Monograph of the genus Pythium. Studies in Mycology 21.

WHITE T. J., T. BRUNS; S. LEE \& J. W. TAYLOR. 1990. Amplification and direct sequencing of fungal ribosomal RNA genes for phylogenetics. In: INNIS M. A, GELFAND D. H., SNINSKY J. J. \& WHITE T. J. (eds.) PCR Protocols: a guide to methods and applications, pp. 315-322. Academic Press, New York.

Recibido el 9 de septiembre de 2014, aceptado el 26 de febrero de 2015. 
